\title{
Is China ready for GM rice?
}

\author{
In an effort to avoid a food crisis as the population grows, China is putting its weight \\ behind genetically modified strains of the country's staple food crop. \\ Jane Qiu explores the reasons for the unprecedented push.
}

\begin{abstract}
$\mathrm{n}$ a paddy field 30 kilometres south of Fuzhou, the capital of China's Fujian province, Wang Feng is surveying a massive green and yellow chessboard before him. Wang, a rice researcher at the Fujian Academy of Agricultural Sciences, and his colleagues have been developing genetically modified (GM) rice strains to resist pest infestation, and have been testing in these plots for a decade. Two strains from Wang's team are now awaiting regulatory approval by the agricultural ministry for commercial growth. It could
\end{abstract} represent the largest commercialization of a GM foodcrop. Rice is a staple for most of the country's 1.3 billion people and a primary source of calories for more than half the world's population.

China's population is set to top 1.45 billion by 2020 , and the country needs to increase grain production by about $25 \%$, a daunting task in the face of increasing urbanization, industrialization, farmland reduction and the efflux of rural workers to the cities. The Chinese government has latched on to transgenic plants as a solution, rolling out a major research and development initiative on GM crops for the next 12 years, including a sizeable investment of 25 billion yuan (US $\$ 3.7$ billion) from the central government and additional matched funding from its provincial counterparts.

\section{The bigger picture}

Like GM initiatives elsewhere, such as in the United States, the move has drawn its share of criticism, with concerns being raised about the practicality and safety of such a push. Scientists warn that a single-minded focus on genetic engineering to enhance pest resistance misses the bigger picture of how to address agricultural production. China is the world's largest rice producer, weighing in with nearly 200 million tonnes, and several observers fear that introducing GM rice could endanger the food supply and the environment. "The consequences would be unthinkable if large-scale cultivation of GM rice were not properly regulated," says
Xue Dayuan, chief scientist on biodiversity at the Nanjing Institute of Environmental Sciences. But in a country where policies are rarely a matter of open debate, government officials warn that the scale of the impending food shortage makes further delays an unaffordable luxury. "This is the only way to meet the growing food demand in China," says Huang

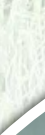

alternating colours. Wang pulls the top from one of the non-transgenic plants. Unrolling its leaves and splitting its stem, he reveals the insecticides' primary target, the stem borer.

Wang says stem borers can affect $3.3 \mathrm{mil}$ lion hectares of rice fields, resulting in a $5 \%$ loss in yields at a cost of 10 billion yuan a year. According to Zhu Zhen, a geneticist at the Beijing-based Institute of Genetics and Developmental Biology, Chinese Academy of Sciences (CAS), who developed the rice strains with $B t$ and $C p T I$ genes, there are no naturally occurring strains that can confer such resistance. After ten years of field testing at a dozen locations, the researchers are confident that farmers would use less pesticide with GM rice strains ${ }^{1}$.

\section{Plagued by pests}

But David Andow, an entomologist at the University of Minnesota in St Paul, says he is unconvinced. In the past few decades, the stem borer has been overtaken by another pest, the brown planthopper (Nilaparvata lugens), which wreaks havoc every spring and has become the main concern of farmers in Asia. Bt and $C P T I$ toxins have no effect on the insect.

Moreover, many simply see GM approaches as ham-fisted in the face of complex ecologies. Kong Luen Heong, an entomologist at the International Rice Research Institute in Los Baños, the Philippines, calls pest-resistant GM crops a short-term fix for long-term problems caused by crop monoculture and overuse of broad-spectrum pesticides. "Pests thrive where biodiversity is at peril," says Heong. "Instead of genetic engineering, why don't we engineer the ecology by increasing biodiversity?"

Indeed, such ecological engineering has proved beneficial. Zhu Youyong, president of the Yunnan Agricultural University in Kunming, and his colleagues have found that growing a mixture of rice varieties across thousands of farms in China could greatly limit the development of rice blast - a fungal rice
Dafang, former director of the Biotechnology Research Institute of the Chinese Academy of gricultural Sciences (CAAS) in Beijing.

Wang is optimistic that his group's pestresistant GM rice will help lead the way. In team planted alternating squ of conventional rice crops and crops genetically modified to produce an insecticidal toxin made by the bacterium Bacillus thuringiensis $(B t)$ gene and the cowpea trypsin inhibitor $(C p T I)$ gene. In the absence of chemical pesticides, $B t / C p T I$ rice thrived, whereas the conventional plants withered, resulting in the chessboard pattern of 
disease - and boost the yield ${ }^{2}$. They have also tested similar practices using different crops and found beneficial effects.

Although GM crops are, in principle, compatible with such an ecological approach, it requires management that has proved hard to achieve within China's agricultural system, which is based on small-scale cultivation, says Xue. Although Bt cotton, the biggest GM crop produced in China to date, has put the cotton bollworm (Helicoverpa armigera) under control, the population of secondary pests, such as mirids, has risen since 2001. That has led to increased pesticide use ${ }^{3,4}$, but still at levels lower than pre-1997, when the cotton was introduced.

\section{Safety concerns}

Debates have also flared because of rice's central role in the Chinese diet. One concern has been that antibiotic-resistance marker genes used in the derivation of the transgenic plants could invariably be taken up by naturally occurring gut bacteria and lead to resistant, pathogenic strains. Both of Zhu Zhen's $B t / C p T I$ rice lines and other $B t$ strains developed elsewhere are free of such markers.

The GM plants must also be shown to be non-allergenic. Composition tests and studies assessing toxicity in non-human animals allow the developers to claim that the GM rice varieties are "substantially equivalent" to unmodified counterparts apart from the target-gene expression. But for food eaten three times a day by a billion people, shortterm animal studies aren't enough to measure equivalence. "If there were a health risk, we would be heading for a major disaster," warns Liu Bing, an expert on science and society in Tsinghua University in Beijing.
Another concern is the potential environmental consequences of transgenes escaping from GM rice to its unmodified crop counterparts through cross-pollination. Several escapes have occurred around the world, including releases of unapproved GM crops such as rice and corn into human consumption streams. For example, in 2006, the European Union halted imports of US rice when an unapproved strain was found in the food supply. Trade resumed, but the problem of accidental cross-pollination, which is thought to have caused the contamination, is one that has not yet been solved. The consensus seems to be that perfect prevention of such events is impossible 5 .

\section{"Using GM rice is the only way to meet the growing food demand." - Huang Dafang}

Lu Baorong, a biodiversity researcher at Fudan University in Shanghai, is concerned about gene flow from GM rice to its wild or weedy relatives. Wild-rice plants are undomesticated strains, whereas weedy rice, which is characterized by its seed scattering and dormancy, is thought to originate from rice crops as a result of mutations. Lu's team and another group have shown that the rate of gene flow from GM strains to wild and weedy rice is $3-18 \%$ and $0.01-0.5 \%$, respectively ${ }^{6,7}$.

"What is most worrying is that such gene flow is cumulative," says Lu. Although rice crops are harvested at the end of the season, wild and weedy rice carrying transgenes would continue to reproduce, allowing the genes to spread, subject to selection.
This could threaten the biodiversity of wild rice, which provides a valuable gene pool for rice breeders (see 'The panda of the plant world') but is already at the brink of extinction in China. In addition, weedy rice with pest-resistant or other fitness genes could have a greater capacity to infest rice fields, causing yield loss. However, $\mathrm{Lu}$ says that these are not inevitable consequences of large-scale cultivation of GM rice. "Proper regulation is the key," he says.

\section{A regulatory mess}

But regulation, says Xue, is where the majority of problems lie. "Field testing is one thing, but the reality is quite another." Although China has had biosafety regulations for GM crops since 1996, their implementation has proved uneven - a fact that most people approached by Nature acknowledged. In some provinces, such as Xinjiang, farmers began large-scale cultivation of $B t$ cotton long before approval was granted, says Xue. In several cases, $B t$ cotton strains were grown without proper labelling, some of which were experimental strains from research institutes.

Cross pollination and labelling slip-ups could be disastrous for China's exports of rice and rice-related products. And proper regulation of GM crops is crucial for delaying the emergence of resistant pests. Many crops, such as cotton and rice, are grown as a monoculture in China, which would select pests that are resistant to the toxins. One way to avoid this from happening is to use seeds that produce high toxin levels; another way is to set aside some land near GM-crop fields for its unmodified counterparts, which would serve as a 'refuge' for insects.

This 'high-dose and refuge' strategy, which

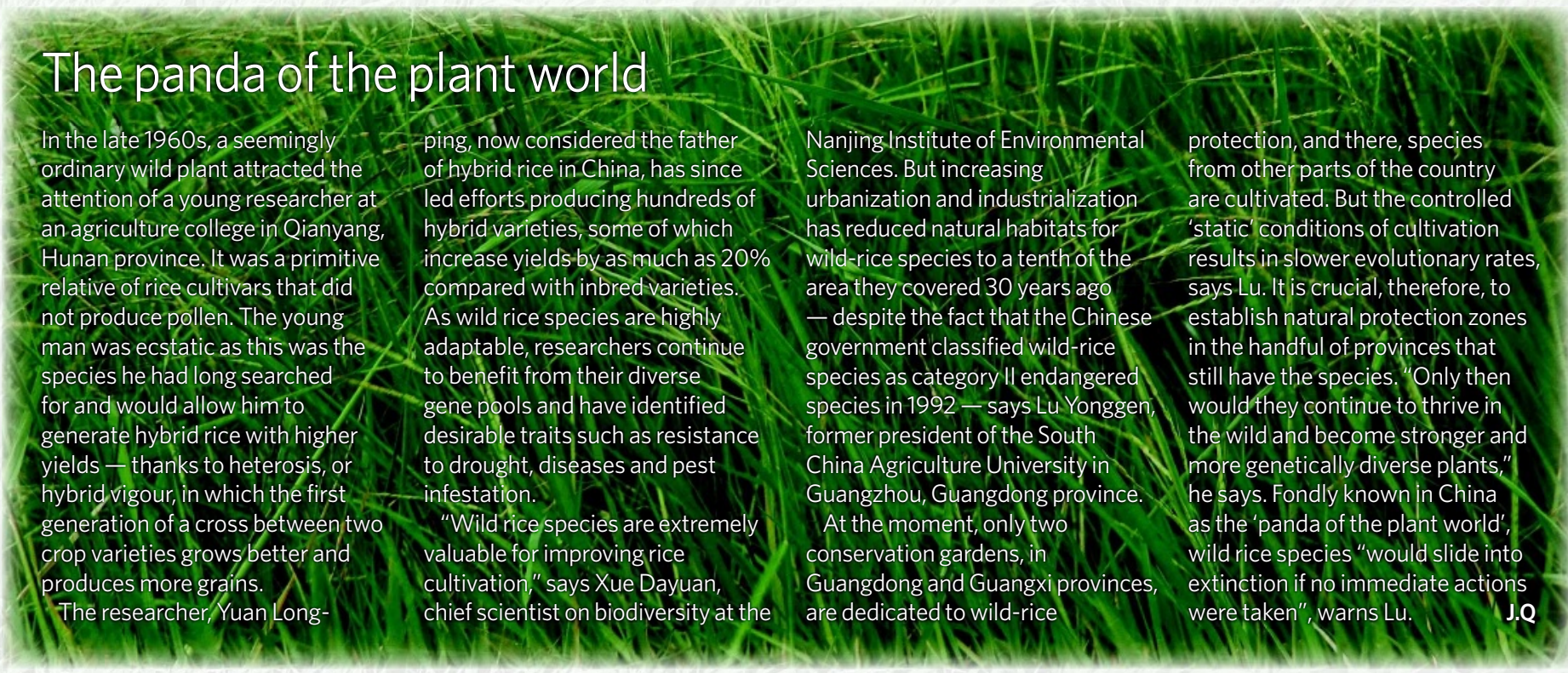




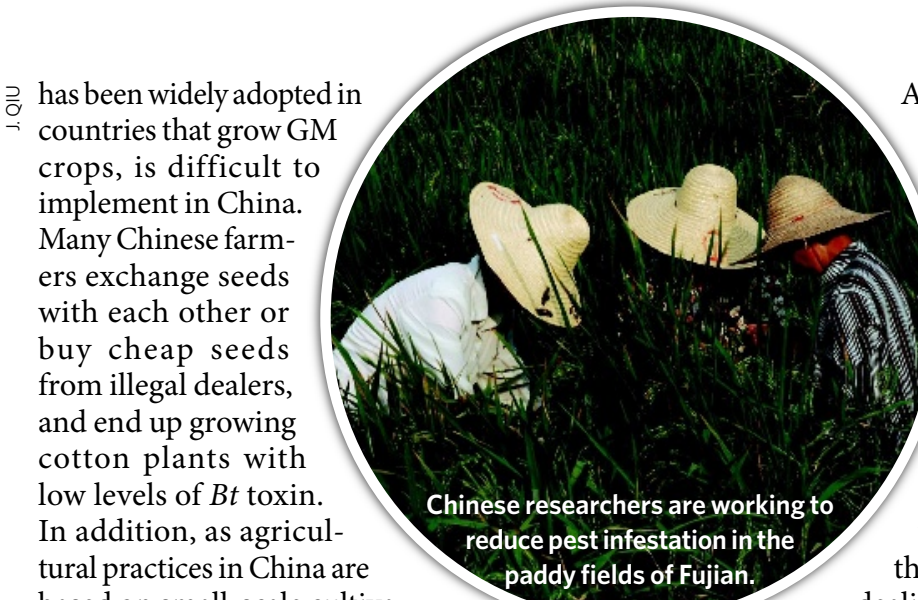
based on small-scale cultivation by individual families with limited resources, $B t$ cotton plants are grown without refuge areas.

Fortunately, the cotton bollworm also attacks crops such as wheat, corn, soya beans, peanuts and vegetables, which are grown next to the $B t$-cotton fields and offer a safety valve against resistance ${ }^{8,9}$. "This is unlikely to happen with $B t / C p T I$ rice because the stem borer feeds only on rice," says Heong. "Therefore, setting aside refuge areas is absolutely essential."

\section{Behind closed doors}

Worryingly, many of the stakeholders, including farmers, bioethicists and environmental groups, aren't being involved in the biosafety evaluation process as spearheaded by the agricultural ministry. The country hails GM rice as a magic bullet for food-production problems and few dissenting opinions are heard. "The whole process is rather opaque," says David Just, an economist at Cornell University in Ithaca, New York. "China is trying very hard to keep the lid on." Experts who express their concerns are often sidelined. Xue, for example, has been repeatedly excluded from biosafety committees that are assessing GM crops.

Despite these concerns, China does need to find a way to feed its swelling population.
Although it has instigated plans to prevent further reduction in farmlands, boosting grain production remains the key to food security. Still, the single-minded focus on genetic modification seems misguided to many. "Genetic-modification technologies just treat the symptoms rather than dealing with the causes," says Hans Herren, president of the Millennium Institute in Arlington, Virginia, and a co-chair of the International Assessment of Agricultural Knowledge, Science and Technology for Development (IAASTD). According to a report released by the IAASTD in April, the main challenges faced by agricultural

\section{"The consequences would be} unthinkable if large-scale cultivation of GM rice were not properly regulated."

$$
\text { - Xue Dayuan }
$$

development around the world are soil fertility, water management and climate change ${ }^{10}$. "Life in the soil is gone after decades of heavy use of pesticides, herbicides and chemical fertilizers," says Manuela Giovannetti, a soil microbiologist at the University of Pisa in Italy. Herren agrees: "Without a concerted global effort to restore soil fertility, genetic modification would be futile."

Xue says he recognizes the potential of genetic modification, but is concerned that huge investment in the technologies - as with China's new initiative - would sap already dwindling attention from improving traditional plant-breeding technologies and conventional farming practices. However, GM strategies have a strong draw for keeping China competitive at the cutting edge of agriculture. A report by the International Service for the Acquisition of Agri-biotech Applications estimates that biotech rice could deliver benefits of $\$ 4$ billion per year for China ${ }^{11}$.

"What is behind all this might be about who controls germ plasm and who owns intellectualproperty rights," says Andow. The scale of the effect that commercial GM rice could have on China and the rest of the world argues for caution. Nevertheless, many interests within the country say that the time to act is now. Huang puts it bluntly: "We cannot afford to think too far ahead but must tackle the present issues."

\section{Jane Qiu writes for Nature from Beijing.}

Huang, J., Hu, R., Rozelle, S. \& Pray, C. Science 308 688-690 (2005)

2. Zhu, Y. et al. Nature $406,718-722(2000)$.

3. Wang, S., Just, D. \& Pinstrup-Andersen, P. Int. J. Biotechnol. 10, 113-120 (2008)

4. Wang, Z. et al. Agric. Sci. China (in the press)

5. Ledford, H. Nature 445, 132-133 (2007).

6. Wang, F. et al. Plant Biotechnol. J. 4, 667-676 (2006)

7. Shivraina, V. K. et al. Crop Protection 26, 349-356 (2007)

8. Wu, K.-M., Lu, Y.-H., Feng, H.-Q., Jiang, Y.-Y. \& Zhao, J.-Z. Science 321, 1676-1678 (2008).

9. Qiu, J. Nature doi:10.1038/news.2008.1118 (2008).

10. Beintema, N. et al. International Assessment of Agricultural Knowledge, Science and Technology for Development: Global Summary for Decision Makers (IAASTD, 2008); available at http://www.agassessment.org/index.cfm?Page=IAASTD $\% 20$ Reports\&ItemID=2713

11. James, C. Global Status of Commercialized Biotech/GM Crops: 2007ISAAA Brief No. 37. (ISAAA, 2007); available at http://www.isaaa.org/Resources/Publications/briefs/37/ executivesummary/default.html 